\title{
El Tercer Sector de Acción Social en las Comunidades Autónomas: ¿modelos de Tercer Sector 0 singularidades territoriales?
}

\section{Vicente Marbán Gallego, Gregorio Rodríguez Cabrero}

RESUMEN: El Tercer Sector de Acción Social (TSAS) ha pasado de ocupar una posición institucional residual a otra de mayor centralidad dentro del sistema mixto de bienestar en España. En el actual contexto de descentralización escasean los trabajos comparativos sobre el ámbito autonómico del TSAS. El objetivo de este texto es analizar el encaje institucional y socioeconómico del TSAS en diferentes regiones españolas. En el artículo comenzamos refiriéndonos a la evolución reciente del TS español y a sus principales características y la completamos con un análisis comparado internacional y regional de los diferentes "modelos" de TS europeos y las principales tendencias de cambio. Finalmente, se explora la existencia de factores diferenciales económico-institucionales, sociohistóricos y de capital social analizando si existe en España un modelo general de desarrollo del TSAS versus modelos autonómicos. El trabajo tiene como base empírica la realización de 48 entrevistas en profundidad y 14 grupos focales realizados en 7 comunidades autónomas españolas entre expertos, directivos y representantes de las organizaciones del TS en el marco del Proyecto PECOTSAS del Programa de I+D+i de excelencia del Ministerio de Economía Industria y Competitividad (RFA: CSO2017-85486-P). Concluimos con la idea de que existen singularidades territoriales sobre las que predomina un estilo común de acción que no permiten referirnos a un modelo estatal de TSAS ni a modelos autonómicos diferenciados.

PALABRAS CLAVE: Tercer Sector de Acción Social, Comunidades Autónomas, regulación, financiación, capital social, sostenibilidad.

CLAVES ECONLIT: L31, H53, Z13. 
Cómo citar este artículo/How to cite this article: MARBÁN-GALLEGO, V. \& RODRÍGUEZ-CABRERO, G. (2021): "El Tercer Sector de Acción Social en las Comunidades Autónomas: ¿modelos de Tercer Sector o singularidades territoriales?", CIRIEC-España, Revista de Economía Pública, Social y Cooperativa, 103, 9-41. D0I: 10.7203/CIRIEC-E.103.21496.

Correspondencia: Vicente Marbán Gallego, Universidad de Alcalá, vicente.marban@uah.es, orcid.org/0000-0002-1825-3829; Gregorio Rodríguez Cabrero, Universidad de Alcalá, orcid. org/0000-0002-8396-9348.

ABSTRACT: The Third Sector of Social Action (TSSA) has gone from occupying a residual institutional position to one of greater centrality within the mixed welfare system in Spain. In the current context of decentralisation of the TSSA, which runs parallel and in a subsidiary manner to that of the Spanish "State of the Autonomies", there are few comparative studies on the regional dimension of the TSSA. The aim of this text is to analyse the institutional and socio-economic fit of the TSSA in different Spanish regions. This article begins by referring to the recent evolution of the Spanish Third Sector and to its main characteristics, followed by a comparative international and regional analysis of the different European Third Sector "models" and the main trends of change. Finally, it explores the presence of differential economic-institutional, socio-historical and social capital factors by analysing whether there is a general model for the development of the TSSA in Spain versus autonomous regional models. The empirical basis of this study is the carrying out of 48 in-depth interviews and 14 focus groups in seven Spanish Autonomous Communities among experts, managers and representatives of Third Sector organisations in the framework of the PECOTSAS project. The PECOTSAS project (Comparative Perspective on the Third Sector of Social Action) has been carried out between 2018 and 2021 and is funded by the 2017 Call for RDI Excellence Projects of the Spanish Ministry of Economy, Industry and Competitiveness (RFA: CS02017-85486-P). We conclude with the idea that there are territorial peculiarities over which a common style of action prevails, which does not allow us to refer either to a state-wide model of TSSA or to differentiated regional models.

KEYWORDS: Third Sector, Autonomous Communities, regulation, financing, social capital, sustainability. 


\section{Expanded abstract}

\section{The Third Sector of Social Action in the Autonomous Communities: Third Sector patterns or territorial singularities?}

The development of the Third Sector of Social Action (TSSA) has responded to a wide range of economic, social and socio-historical conditioning factors which are reflected in theoretical and empirical studies, the results of which coincide: TSSA organisations have experienced very significant growth and have gone from occupying a residual institutional position in the Spanish welfare system to one of greater centrality. This institutional positioning and the very growth of the TSSA have taken place in a system of government (Autonomous Communities) which has introduced greater diversity in decentralised welfare systems in the fields of health, education, social services and, more recently, long-term care. The decentralisation of the welfare state in Spain has had a certain impact on the intensity of protection in the different territories, which has opened the way for the TSSA to become a rebalancing actor in the face of territorial inequality.

The working hypothesis is that the Spanish welfare state has been configured in parallel to the development of the "State of the Autonomies", allowing the Third Sector to develop in a relatively differentiated manner in each Autonomous Community. In order to test this hypothesis, the aim of this article is to analyse the institutional and socio-economic setting of the TSSA in different Spanish regions. The research investigates a series of differential factors in the development of the TSSA in the Autonomous Communities in order to assess whether there are different Third Sector logics or models in the different territories under analysis.

From a methodological perspective, a review of the literature and of secondary sources has been carried out to analyse the recent evolution of the Spanish Third Sector, the European and regional Third Sector models and the trends of change (reflected in the introduction and second section). In order to analyse the institutional and social fit of the TSSA in the Spanish "State of the Autonomies" (third section), primary sources have been used; in particular, 48 indepth interviews and 14 focus groups conducted among experts, officials of regional public administrations, managers and representatives of the organisations of the Third Sector in seven significant Autonomous Communities (Andalusia, Castile and Leon, Catalonia, Community of Madrid, Community of Valencia, Basque Country and Region of Murcia) between the months of April and September 2019 and in April-May 2021. This research is part of the PECOTSAS project (Comparative Perspective on the Third Sector of Social Action) carried out between 2018 and 2021 and funded by the 2017 Call for RDI Excellence Projects of the Ministry of Economy, Industry and Competitiveness (RFA: CS02017-85486-P). 
We highlight the following results from the literature review:

1. The significant deployment of both the TSSA in Spain (1.4\% of GDP in 2018), and of the whole of the Third Sector in the EU (13\% of the total European workforce in 2014) with a very significant weight of the human resources being generated in non-profit entities (59\% of the whole of the Third Sector), of the provision of services (72\%) and of self-financed income (54\%). Within this general pattern of the European Third Sector, however, there are differences between regions representative of the different European welfare state regimes which have been attributed to different approaches. The latter adequately explain some differences but not others, such as the response of the Third Sector to state shortcomings in meeting the heterogeneity of demand, the differences between countries in terms of values, traditions, attitudes and cultural feelings, or the power relations between labour movements and their political extensions in different countries during their periods of industrialisation and modernisation (Social Origins Theory).

2. The exploratory and tentative character of analyses of European Third Sector models (Anglo-Saxon or liberal, continental, Nordic or social democratic, statist and Mediterranean), although in no welfare regime is there a closed model, but rather generic forms of Third Sector. At the regional level, there is a lack of comparative research on possible regional Third Sector models in Spain. Most of these studies on the Third Sector have a more comprehensive, all-encompassing and sectoral character and do not delve into the comparative level between the Autonomous Communities.

The main weakness of these European models is that they tend to be established on the basis of similarities in the development of the Third Sector within different welfare state regimes, which shows that even to this day, social research on the Third Sector does not carry the weight and importance accorded to studies on the welfare state, of which it tends to be an analytical appendix. This is compounded by the existence of increasingly complex and global processes in the European and national contexts, the result of which is imitation and convergence in a series of common trends in the Third Sectors of the different countries, described in the article and modulated by the specificity of each country's national path, which are blurring the existence of possible Third Sector models.

In short, after reviewing the literature, it has been found that comparative regional studies such as the one presented here are scarce in the different countries, which is what confers on this study its main added value and originality.

With regard to the question of whether there is a state-wide model or differentiated regional TSSA models in Spain, we can conclude the following on the basis of the qualitative study:

1. There is a "common style of action" in the TSSA as a whole, but not as a single actor acting with a single logic. This common style of action would be characterised by three features: institutional strengthening of social dialogue, led by the large organisations and platforms; reinforcement of joint work through the creation of networks and internal forms of collaboration; and openness to collaboration with other social and economic actors to ensure sustainability. However, despite this common style, it is not possible 
to speak of a TSSA model given the internal diversity of the sector and of each sectoral sphere as well as the constant tension in the discourses on the development of the TSSA in Spain between the centripetal forces that lead it towards a common universalist logic (defence of rights, promotion of social participation, fight against social exclusion) and the centrifugal forces that lead it towards a logic of differentiation (functional adaptation to the Autonomous Communities, adjustment of action to the territory and monitoring of its own cultural and historical path).

2. There are territorial singularities rather than specific models of regional Third Sectors that are rooted in their social history and the way they relate to the welfare state. Rather than models, we should speak of regional and territorial traditions. Territorial specificities and styles are of varying degrees and at the same time share common features, albeit unevenly, throughout the territory of the Spanish state. These common features at the regional level would be the following: a) the integration of the TSSA within mixed systems of social services; b) the development of social capital or reinforcement of internal and external social cohesion as the overarching objective among TSSA organisations; $c$ ) the extension of TSSA regulation accompanied by its stable recognition by the public sector in third sector laws, social services laws or civil dialogue roundtables; and d) the functional accommodation of the TSSA to the regional and territorial governments (provinces and municipalities) in the management of social services and social services programmes. This accommodation has reinforced a functional differentiation of the sector, but not a structural one. The social purpose sector has contributed in its own way to the development of social rights in Spain, but to achieve this objective it has had to functionally adapt to the public policies on which it partly depends in terms of regulation and funding. On the other hand, such accommodation has also required an adaptation of the public administrations to the territorial and organisational characteristics of the TSSA. We are faced with an unequal complementarity, especially in the case of small organisations, and relatively symmetrical collaboration in the case of large entities and platforms.

3. It is necessary to achieve the sustainability of social entities as a way of reconciling the sector's mission with its territorial diversity, along four complementary axes: a) economic-financial sustainability: based on the plurality of relatively stable sources of funding and the use of subsidies, as a capacity-building tool, and agreements and conventions to provide greater stability; b) organisational sustainability, encouraging networking, joint contracting of activities and the creation of ad hoc consortia to bid for tenders; c) social sustainability, i.e. the capacity of the TSSA to give space to citizens, both to the people affected and to the population in general; and d) institutional sustainability: the capacity to create internal social cohesion and improve the capacity for dialogue with other social actors and, if possible, stable alliances with public authorities across the TSSA as a whole. 


\section{Introducción}

El desarrollo del Tercer Sector de Acción Social (TSAS) responde a un amplio elenco de condicionantes económicos, sociales y sociohistóricos plasmados en trabajos teóricos y empíricos cuyo resultado es coincidente: las organizaciones del TSAS han experimentado un crecimiento muy significativo y han pasado de ocupar una posición institucional residual en el sistema de bienestar español a otra de mayor centralidad.

Este reposicionamiento del TSAS en España es fruto sobre todo de la confluencia de tres factores (Marbán, Pérez and Rodríguez, 2020):

a) La reconstrucción de la sociedad civil española a partir de la transición democrática y de su consolidación en el tiempo (período aproximado entre 1977 y 1989). Ello supuso una rápida creación y expansión de organizaciones sociales debido a la transformación de diferentes movimientos de personas afectadas por diferentes problemas (discapacidad, drogodependencias, tercera edad, entre otras) en $0 \mathrm{NG}$ estables con más poder organizativo que capacidad de movilización social (Casado, 2015).

b) La configuración de un sistema de bienestar mixto basado en una estructura triangular en la producción del bienestar (Estado, mercado y Tercer Sector) donde éste último, en paralelo a la construcción del Estado de Bienestar, se ha desarrollado como colaborador dependiente de sus políticas sociales (reforzado por un marco de regulación y de financiación favorable a la integración del TSAS en el régimen de bienestar).

c) La creciente influencia de las estrategias de inclusión promovidas por la UE favoreciendo una participación e influencia más activas en el sistema mixto de bienestar español. Esto le llevó a ser un actor social con mayor representación institucional y protagonismo en el diseño y desarrollo de las políticas sociales (Comisión Europea, 2010).

El crecimiento del TSAS se plasma en indicadores de financiación, empleo y voluntariado muy significativos. Así, de acuerdo con el último estudio de la Plataforma de ONGs de Acción Social (POAS, 2020) se estima que los ingresos del sector representaron en 2018 el 1,37\% del PIB nacional (equivalente, por ejemplo, a sectores como los de consultoría informática o la industria cultural). En el TSAS predomina de manera abrumadora el pequeño tamaño económico: en 2018 el 49,5\% de las entidades tenían ingresos inferiores a 30.000 euros anuales (25,0\% en 2008). 0 de otra manera, las entidades con ingresos inferiores a 300.000 euros anuales eran el 80,2\% del total en 2018 (63,7\%). Las entidades con más de 300.000 euros de ingresos, que eran el 36,3\% en 2008, son el 19,8\% en 2018. Por su parte, las entidades con ingresos superiores a 1 millón de euros son el 8,5\% en 2018 (17\% en 2008). La crisis de 2008 y su amplio impacto ha producido un retroceso relativo en la capacidad de captación de ingresos y, al mismo tiempo, se ha intensificado la polarización del sector desde la perspectiva de los ingresos (Rodríguez Cabrero, 2020)

La crisis de 2008 ha supuesto un retroceso de la financiación pública. Por su parte la financiación propia se ha más que duplicado entre 2008 y 2018 (ver Tabla 1). 
Tabla 1. Distribución de la procedencia de los ingresos del TSAS

\begin{tabular}{|c|c|c|c|c|}
\hline$\%$ & 2008 & 2010 & 2013 & 2018 \\
\hline Financiación pública & 61,3 & 60,0 & 55,3 & 41,4 \\
\hline Financiación privada & 23,9 & 18,2 & 19,4 & 26,0 \\
\hline Financiación propia & 14,8 & 21,8 & 25,3 & 32,6 \\
\hline Total & 100,0 & 100,0 & 100,0 & 100,0 \\
\hline
\end{tabular}

Fuente: Elaboración propia en base a FLV 2010, 2012, POAS, 2015 y 2020.

En 2018, el TSAS tenía un volumen de empleo de 577.230 personas, el 67,5\% de ellas son mujeres. El sector crece en una década el 9,1\%, si bien se concentra casi en exclusiva en las entidades singulares (Caritas, Cruz Roja y ONCE). El TSAS supone el 3\% del empleo de la economía española. En 2018 casi el 46\% de todas las entidades tenían menos de 5 personas empleadas, lo que refleja una estructura organizativa con acentuados rasgos minifundistas. Con empleo a tiempo completo se encuentra el 46,5\% de las personas contratadas y la contratación temporal afecta al 37,5\% de todas ellas. Finalmente, en este sector el peso del voluntariado es muy importante. El volumen de personas voluntarias crece el 31,2\% entre 2008 (803.171 personas voluntarias) y 2018 (1.054.325). En este último año este voluntariado aportó 313.586.104 horas con un valor económico equivalente a 1.769 millones de euros y 171.734 empleos a tiempo completo (Pérez Yruela y Rodríguez Cabrero, 2020).

El impacto social del TSAS puede medirse en base a diferentes indicadores. Uno de ellos es relevante: la población beneficiaria. En 2018 las entidades sociales realizaron 42 millones de intervenciones, equivalente a 25 millones de personas beneficiarias, el mismo volumen que en 2008. La crisis de 2008 supuso un esfuerzo de respuesta notable por parte del TSAS que se concretó, en pleno impacto social de la crisis (2013) en 53 millones de intervenciones personas, equivalente a más de 31 millones de personas beneficiarias.

Este crecimiento del TSAS se ha producido en un contexto socio-político articulado sobre un sistema autonómico que ha introducido una mayor diversidad en los sistemas descentralizados de bienestar en los ámbitos de la sanidad, la educación, los servicios sociales y, recientemente, en los cuidados de larga duración. La descentralización del Estado de Bienestar en España ha tenido cierto impacto en la intensidad de la protección social y el bienestar en los distintos territorios. En aquellos casos donde la descentralización ha acentuado las diferencias de acceso a los servicios de bienestar entre territorios, el TSAS ha ido encontrando su espacio como actor de reequilibrio frente a la desigualdad territorial. Y lo ha conseguido gracias a su "posición privilegiada en el conocimiento de los problemas sociales y de los métodos para enfrentarlos... y su papel crucial en el diseño y la ejecución de las políticas contra la pobreza y la exclusión social" (reconocida en el preámbulo de la Ley 43/2015 del Tercer Sector de Acción Social aprobada en octubre de 2015). Un estudio reciente (Rodríguez Cabrero y Marbán, 2015) sugiere que la descentralización del Estado también ha favorecido una relación más directa de las organizaciones del TSAS con los ámbitos local y regional produciéndose una especializa- 
ción funcional en el sector donde las organizaciones paraguas y las grandes $\mathrm{ONG}$ actúan a nivel de todo el Estado y las ONG de tamaño medio y pequeño lo hacen en el nivel local.

En definitiva, como sostienen Aguiar y Pérez Yruela (1995:216) en la medida en la que el Estado de Bienestar se ha ido configurando en paralelo al desarrollo del Estado de las Autonomías, el Tercer Sector también se ha desarrollado de manera relativamente autónoma en cada CCAA. Para averiguar si esto es así nos preguntamos en este artículo si existen una serie de factores diferenciales en el desarrollo del TSAS en las CCAA y cómo ello puede afectar, si fuera el caso, a la existencia de distintas lógicas o modelos de Tercer Sector en los diferentes territorios.

Para responder a esta pregunta, el texto se ha estructurado del siguiente modo: primero, se comienza introduciendo la evolución reciente del TSAS y sus principales características. Después, se realiza un análisis comparado internacional y regional de los diferentes TS europeos, la existencia de posibles modelos de TS y las principales tendencias de cambio comunes. En tercer lugar, se analiza si existe en España un modelo general de desarrollo del TSAS versus modelos autonómicos. Se concluye destacando que el proceso de expansión y desarrollo del TSAS en España ha seguido, en gran medida, la senda de desarrollo de un Estado de Bienestar descentralizado con el que colabora en la aplicación de diferentes políticas sociales y de cuyos recursos financieros depende en parte. Bajo este modelo de Estado de Bienestar el TSAS se ha configurado de manera dual: por una parte, ha creado progresivamente un estilo común en cuanto a la misión, funciones y creación de modos de colaboración interna y de interlocución con el Estado; por otra parte, en cada territorio el TSAS ha combinado su senda histórica de desarrollo con la adaptación específica a las políticas sociales territoriales. Un estilo y formas de adaptación no lejanas de las que se han producido en los diferentes modelos nacionales europeos.

\section{El Tercer Sector en perspectiva comparada europea: ¿modelos? y tendencias comunes}

El significativo crecimiento y la centralidad institucional del TS es un fenómeno generalizado en la mayor parte de los países de la UE. Según Salamon and Sokolowski (2018b) en 2014 el TS de la UE 27, Reino Unido y Noruega ${ }^{1}$ empleó a más 29 millones de personas entre personal remunerado (13 millones) y voluntario (16 millones) situándose como el sector que más recursos humanos aportó en Europa (el 13\% de la mano de obra) tras los sectores de comercio e industria. Con la excepción de los países del Este de Europa, donde el 70\% de estos recursos

1. Engloba a las Entidades No lucrativas, las cooperativas y mutualidades, las empresas sociales y actividades de voluntariado directo. La mayoría son entidades no lucrativas (59\%), seguida del voluntariado directo (31\%), cooperativas y mutualidades (9\%) y tan solo un 1\% (datos de solo 9 países) de empresas sociales. 
humanos se concentró en forma de voluntariado directo, la mayor parte del empleo se generó en las entidades no lucrativas (59\%) aunque con diferencias destacables entre zonas geográficas (Países nórdicos: 71\%; Sur de Europa: 50\%; Centro-Oeste de Europa: 60\%). En los países del sur de Europa destaca el alto porcentaje de empleo en cooperativas (16\%) comparado con la media europea (9\%) y los países nórdicos (6\%) y del Este (8\%).

La mayor parte de estas personas se dedicó a la prestación de servicios (72\%) y a funciones expresivas (24\%). En los países nórdicos esta tendencia se invierte y es, de largo, la zona geográfica donde más predomina la función expresiva por encima de la prestación de servicios.

Los ingresos proceden mayoritariamente de la financiación propia (pagos privados por la venta de bienes y servicios, cuotas de socios e ingresos por inversiones) (54\%), seguido de financiación pública procedente de subvenciones, contratos y reembolsos por servicios prestados a las administraciones públicas (37\%) y un 9\% de financiación privada por donativos de particulares, fundaciones y empresas. De nuevo encontramos diferencias significativas entre zonas geográficas: la financiación propia es claramente predominante en los países nórdicos y la financiación gubernamental lo es en los países del centro y oeste de Europa. Los ingresos privados de carácter filantrópico tienen un peso mucho más relevante en los países del Este (19\%) que en otros espacios geográficos europeos.

Estas diferencias entre países o regiones europeas ponen de manifiesto la compleja delimitación de un modelo o modelos de TS europeo y las causas subyacentes que las explican.

Tales diferencias se han pretendido explicar atendiendo a las teorías económicas convencionales que atribuyen el desarrollo del TS como respuesta a fallos del Estado para atender la heterogeneidad de la demanda (Weisbrod,1977; James 1987) Hansmann. (1987). Estas teorías, no obstante, fracasan cuando se contrastan con las cifras presentadas al no explicar adecuadamente el mayor crecimiento del TS precisamente en Estados de Bienestar de amplia cobertura e intensidad protectora y con un elevado gasto social en los que se han establecido relaciones muy sólidas de partenariado con el TS en servicios sociales de responsabilidad pública.

Para comprender el desarrollo del TS en distintas regiones europeas también se ha recurrido a las diferencias entre los países en cuanto a valores, tradiciones, actitudes y sentimientos culturales de raíz religiosa. Estas diferencias, no obstante, no alcanzan a explicar aquellas que existen entre el TS de países con grandes similitudes culturales y religiosas (Salamon and Sokolowski, 2018a).

Autores como Salamon et al (2017) (Teoría de los Orígenes Sociales) por su parte, atribuyen las diferencias a las relaciones de poder entre actores sociales concretos (administraciones públicas, Iglesia, movimientos sociales, sindicatos, élites políticas, industriales, rurales, comerciales, terratenientes.....) cuyas acciones se orientan hacia normas y valores culturales alineados con sus predisposiciones e intereses de grupo. En particular, vinculan el desarrollo del Tercer Sector a las diferentes configuraciones de las relaciones de poder entre movimientos laborales y sus extensiones políticas en diferentes países durante sus periodos de industrialización y modernización. Como resultado, de manera simplificada, determinan la existencia de cuatro "modelos" del TS: 
1. Un modelo liberal (Reino Unido) compuesto por un importante tejido de organizaciones de TS muy dependientes de aportaciones privadas por cuotas y filantropía. Su arraigo sociohistórico vendría explicado por la consolidación del poder político y económico de las élites conservadoras industriales y comerciales durante el periodo de industrialización cuya orientación política e intereses económicos se inclinaban hacia la confianza en los mercados y en la iniciativa privada con un desarrollo contenido del Estado en los asuntos sociales.

2. Modelo de colaboración de bienestar (Welfare Partnership pattern) característico de la mayoría de los países del centro y oeste de Europa. En ellos, aunque las élites industriales y los terratenientes conservadores mantuvieron parte de su poder, este se vio condicionado por la creciente presión ejercida por el auge de la clase trabajadora y de las organizaciones sindicales. Ello condujo a un modelo de protección del bienestar social patrocinado por el Estado y canalizado a través de organizaciones voluntarias privadas adscritas mayoritariamente a instituciones religiosas conservadoras que colaboraban con los gobiernos en la prestación de servicios de bienestar financiados con fondos públicos.

3. Modelo socialdemócrata de TS, propio de los países nórdicos. Se trataría de un TS surgido al calor del desplazamiento de las élites terratenientes por la clase obrera, la clase agraria minifundista y profesionales urbanos. Ello propició la creación de un entorno más favorable para el desarrollo de unos servicios de bienestar social prestados directamente por las administraciones públicas como derecho objetivo de ciudadanía que a su vez permitió liberar tiempo para la participación y desarrollo del TS en otros ámbitos de corte más expresivo como la cultura, el deporte y el ocio.

4. Modelo "estatista" propio de países de modernización tardía como Rusia, Turquía, o los países de Europa del Este (también España y Portugal, según estos autores). En ellos, según los casos, los líderes militares, los altos funcionarios, los profesionales urbanos o las élites modernizadoras tomaron las instituciones del Estado con fines desarrollistas y restringieron libertades básicas como el derecho de asociación. El resultado fue un lento crecimiento de las organizaciones de la sociedad civil de carácter más expresivo.

Esta teoría aplicada a tipologías de modelos de TS resulta muy aleccionadora y tiene una alta capacidad explicativa del germen y sustrato que aún permanece en el desarrollo del TS de buena parte de los países analizados como consecuencia de las relaciones de poder acaecidas durante los primeros procesos sociohistóricos de industrialización y modernización. Sin embargo, también adolece de algunos puntos débiles. En primer lugar, sus autores afirman que "la teoría de los orígenes sociales no sólo puede explicar la evolución actual sino también ayudar a prever el futuro" (Salamon and Sokolowski, 2018b:75) pero parecen no tener en cuenta que esas relaciones de poder y los intereses de los stakeholders se construyen y reconstruyen, cambian con el tiempo y se ven sometidos a fuerzas centrífugas y centrípetas relacionadas con procesos más complejos, entrópicos y globales que afecta al TS de la mayoría de los países. Estos procesos tienden a difuminar los factores sociohistóricos que fundamentan la génesis del TS de esta teoría, como comentaremos más adelante. En segundo lugar, no analizan con la 
necesaria profundidad la importancia de los procesos de descentralización de los Estados de Bienestar y su impacto en el desarrollo del TSAS.

Existen otros intentos de clasificar el TS recurriendo también al análisis de casos nacionales representativos de los diferentes regímenes de bienestar. Es el caso de los realizados por Antares Consulting y la Fundación Luis Vives (Fundación Luís Vives, 2011) sobre Modelos Europeos en la evolución del Tercer Sector Social y el trabajo elaborado para la Plataforma de ONGs de acción social por Rodríguez Cabrero y Marbán Gallego (2015). Del análisis de los trabajos mencionados se pueden perfilar algunos "modelos" tentativos de TS:

1. Modelo anglosajón o liberal, cuyo máximo exponente sería el Reino Unido, con raíces históricas asistencialistas organizadas en torno a las "Charities" como organizaciones no lucrativas con amplia autonomía financiera y capacidad de autorregulación (Salamon and Sokolowski, 2018a). Al mismo tiempo estas organizaciones están muy integradas en el ámbito local. La descentralización del TSAS es un rasgo característico de este modelo, lo que supone una amplia diversidad de estilos locales de acción. El TSAS o Charities es una red local de entidades que no conforman un modelo como tal, pero que se guían por una práctica tradicional de colaboración y de cooperación, desde la máxima autonomía posible, con el sector público local.

Este modelo asistencial de perfil eminentemente no lucrativo que, con el tiempo, ha ido tomando una deriva cada vez más gerencialista, ha formado parte tanto de un proyecto político de sociedad comprometida (visión laborista) como compasiva (visión conservadora) (Rodriguez Cabrero y Marbán Gallego, 2015). Como resultado de diferentes cambios políticos y en los discursos ideológicos este modelo ha ido basculando entre un incipiente modelo de colaboración de bienestar con el Estado (tras la Segunda Guerra Mundial; Tercera Vía del gobierno Blair: 1997-2010) y un modelo liberal (hasta la expansión del estado de bienestar británico tras la Segunda Guerra Mundial;) ahora neoliberal (era Thatcher-gobiernos conservadores:1979-1997; gobiernos Cameron- May-Johnson- la "Gran Sociedad" sustituyendo al "Gran Gobierno": 2010-actualidad) (Kendall et al. 2016). Este modelo se caracterizaría por "un tercer sector financiado de forma independiente y con hostilidad hacia la participación del Estado en términos de gasto público" (Zimmer and Pahl, 2018:142).

2. Modelo continental, característico de países centroeuropeos como Alemania, Países Bajos o Austria. En ellos, el término Tercer Sector está más claramente identificado con las organizaciones no lucrativas. La Economía Social, fundamentalmente Cooperativas y Mutualidades, tiene una vocación más comercial y laxa en cuanto a distribución de beneficios, lo que la acerca más al sector mercantil (Salamon and Sokolowski, 2018a). En este modelo, sobre todo en Alemania, el TS hunde sus raíces en un tipo de sociedad civil basado la doble idea hegeliana de lograr al mismo tiempo un Estado y una sociedad civil fuertes (Zimmer, 1999) bajo el principio de subsidiariedad, si bien bajo la regulación y protección del primero (Rodriguez Cabrero y Marbán Gallego, 2015). Este principio de subsidiariedad y por ende, el modelo de integración neocorporativa del TS en el régimen de bienestar se han visto comprometidos por el avance de políticas neoliberales y de liberalización de servicios de la Unión Europea. Las entidades del TS lo han resuelto con un mayor gerencialismo y profesionalización de la gestión, lo que unido a la larga tradición y experiencia en la prestación de servicios de bienestar, les ha permitido com- 
petir con éxito con los proveedores comerciales, consolidar su posición y mantener su buena reputación y relación institucional con las AAPP en la provisión de servicios de bienestar. Todo ello a costa de debilitar, en parte, la esencia del TS debido a los siguientes factores: a) una mayor competencia interna entre las propias organizaciones sociales como consecuencia de la reducción del gasto social (Rodríguez Cabrero y Marbán Gallego, 2015), b) el debilitamiento de la misión social y cívica de las entidades; c) el desplazamiento de los profesionales de trabajo social por gestores formados en administración de empresas y, por todo lo anterior, d) un menor atractivo de las organizaciones del Tercer Sector (OTS) para los voluntarios que se ha visto agravado por el debilitamiento de los vínculos ciudadanos con dos de los principales pilares del voluntariado como son el católico y el socialdemócrata (Zimmer and Pahl, 2018).

Dentro de este modelo continental existen variantes nacionales que, en general, coinciden en que el TSAS está altamente integrado en el Estado de Bienestar, adaptado a la descentralización de las políticas sociales en los lánder y provincias y con sistemas de articulación del conjunto del TSAS a través de grandes redes sectoriales y generales.

3. Modelo Nórdico, con Suecia o Noruega como países más representativos, en los que el TS tiene una importante tradición histórica, en cierto modo velada por el predominio del Estado de Bienestar en la producción de bienestar (Buendía, 2012). En estos países no existe una denominación común de Tercer Sector dada la amplia diversidad de organizaciones existentes y de denominaciones (sociedad civil, movimientos sociales, economía social, organizaciones voluntarias...). El concepto de Economía Social no está generalizado y tiende a estar más orientado hacia el mercado, sobre todo en las cooperativas de consumo, producción y vivienda (Salamon and Sokolowski, 2018a). En los países nórdicos, como se ha señalado, predomina la función expresiva por encima de la de prestación de servicios. La financiación propia es claramente predominante fruto del papel protagonista de las administraciones públicas en la prestación de servicios y a la larga tradición de participación de las organizaciones sin ánimo de lucro y del voluntariado en las actividades de defensa de derechos y de deporte (Sivesind and Selle, 2010).

Después de largas décadas de predominio socialdemócrata, la crisis fiscal de principios de los 90 y el ascenso al poder de la coalición liberal-conservadora en diferentes periodos de los 90 y del presente siglo precipitaron dos aspectos que están teniendo una influencia progresiva en los fundamentos del Estado de Bienestar y del TS de los países nórdicos: a) la introducción de herramientas propias de la Nueva Gestión Pública (New Public Management) para regular, en un marco de mayor competencia, las relaciones entre los poderes adjudicadores públicos y los proveedores de servicios sociales y, b) el avance de postulados neoliberales que, aunque no eran mayoritarios, empezaban a cuestionar la capacidad de las instituciones públicas para responder adecuadamente a las necesidades sociales. Todo ello favoreció la apertura de la prestación de servicios de bienestar al mercado y a la economía social en detrimento del rol del sector público (Zimmer and Pahl, 2018:146). En esta evolución del TS, sintéticamente considerada, hay que destacar la intensa adaptación del TS al ámbito municipal, donde se definen y en gran medida se financian las políticas sociales y, por otra parte, la creación de redes organizativas sectoriales que contribuyen a forjar su cohesión interna. Como en los modelos 
anteriores no existe un modelo del TS nacional sino una amalgama coordinada de sectores de actividad con capacidad de negociación e interlocución social y política.

4. Los países del Este de Europa, en términos generales, se asemejan a lo que podría considerarse como un modelo de TS post-estatista en construcción que avanza lentamente hacia fórmulas de cooperación con la administración pública. No obstante, en la práctica, buena parte de estos países no responden a un modelo claro de TS como consecuencia de la influencia combinada de un pasado de pertenencia a un modelo de estado autoritario y su presente democrático pro-UE que el TS de los distintos países del Este ha ido asimilando a diferente ritmo. En el desarrollo del TS de algunos de estos países, en general, todavía perduran reminiscencias del modelo estatista autoritario de desarrollo controlado del asociacionismo, muy centrado en el ámbito de las iglesias, los deportes, gremios profesionales y el cooperativismo centralizado de consumo y producción. Ello podría explicar el actual desarrollo contenido, embrionario y fragmentado de las instituciones más formales del Tercer Sector comparado con sus vecinos centroeuropeos (Zimmer and Pahl, 2018) ${ }^{2}$, el papel predominante de las organizaciones expresivas en el ámbito del ocio y el deporte y la todavía limitada colaboración con las administraciones públicas en la provisión de servicios sociales. Por el contrario, la adhesión a la UE y los fondos europeos han favorecido un espacio más favorable para el desarrollo y revitalización de la actividad del TS (Bežovan, 2016). Se trata de una financiación muy relevante en la medida en la que, comparados con otros Estados de la UE, el TS de los países del Este, en general, tiene una mayor dependencia de los ingresos privados de carácter filantrópico y donde los ingresos por provisión de servicios son limitados bien por la posición de monopolio del Estado en la prestación de servicios sociales y públicos (por ejemplo, en Eslovenia, República Checa) (Bežovan, 2016) o bien, por la falta de conciencia pública y de confianza de los ciudadanos y autoridades estatales en la profesionalidad y la capacidad de las OTS de servicios sociales (Polonia o Croacia) (Zimmer and Pahl, 2018).

Si bien el término "sector no lucrativo" gozó de cierta popularidad en los países del Este durante el proceso de transición política del comunismo a la democracia, el de Economía Social la ha ido adquiriendo a medida que estos países se han ido incorporando a la UE, aunque su peso sigue siendo modesto (emplea a menos del $2 \%$ de la población activa) comparado con buena parte de los países del centro de Europa (9-10 \%) (Monzón y Chaves, 2016). En consecuencia, no existe un modelo de TSAS ni una articulación interna de lo que es aún un sector rudimentario en fase de expansión.

5. El modelo mediterráneo de TS, que englobaría fundamentalmente a Italia y España, a otro nivel Portugal y Grecia, se caracterizaría por un TS que, a diferencia de los países del Este, habría completado el tránsito de un modelo estatista de desarrollo controlado del asociacionismo y de represión de libertades (sobre todo en el caso español) a un modelo de relación instrumental o de cooperación económica entre el TS y la administración pública. La integración en la UE, el desarrollo del EB (incluidas sus propias limitaciones), los procesos de secularización de la sociedad y el ascenso de los movimientos sociales (caso de Italia) y el

2. Como ya se ha señalado, el 70\% de los recursos humanos del TS en los países del Este se concentran en forma de voluntariado directo en vez de en recursos humanos de las organizaciones. 
asociacionismo vecinal (España) habrían contribuido al desarrollo actual del TS dentro de un modelo mixto de bienestar que se encuentra en una etapa avanzada de consolidación gracias a fuertes estructuras de segundo nivel y una buena aceptación social.

El TS de estos países, muy enraizado históricamente en la Iglesia Católica se ha ido transformado progresivamente en un sector más diversificado y dependiente de las administraciones públicas. En ambos casos, la familia desempeña un importante rol como red primaria de solidaridad y apoyo social, compensando las carencias de cobertura en servicios de bienestar del sector público (Zimmer and Pahl, 2018) y complementando al TS, incluso contribuyendo a construirlo, como en el caso de algunas organizaciones para personas con discapacidad en España.

Los términos de Tercer Sector y de Economía social gozan de buena aceptación en los países mediterráneos. En general, en el espacio del Tercer Sector tienden a considerarse tanto a organizaciones no lucrativas (asociaciones y fundaciones) como la Economía Social (sobre todo cooperativas y mutualidades). En España, a menudo el término de Economía Social viene a utilizarse como sinónimo de Tercer Sector. (FLV, 2012) diferenciando entre entidades productoras de servicios no de mercado (asociaciones y fundaciones) y de mercado (cooperativas, mutualidades, empresas sociales, entre otras) (Monzón y Chaves, 2016). En ambos países la economía social tiene un peso e influencia notables (generan en torno al 8\% del empleo) (Monzón y Chaves, 2016).

A nivel regional, en España no abundan los trabajos de carácter comparado ni exploratorio de posibles modelos regionales de TS. La mayor parte de los trabajos sobre el TS tiene un carácter general (Ruiz de Olabuénaga, 2000; Barea y Monzón, 2002; García Delgado, 2005) o sectorial (centrados en la acción social) (entre otros: Pérez Díaz y López Novo, 2003; Rodríguez Cabrero, coord., 2003; Fundación Luís Vives, 2010, 2012; Systeme, 2015; Rodríguez Cabrero et al, 2015, POAS, 2020). Los trabajos más destacados a nivel regional son de calidad, pero no descienden a nivel comparado entre las Comunidades Autónomas. Es el caso de los realizados por CIRIEC para la Comunidad Valenciana (Chaves y Monzón, 2020), la Universidad Pablo de Olavide (González y Jaraíz, 2020), la Taula d'Entitats del Tercer Sector Social de Catalunya (Codina, 2016) o el Observatorio del Tercer Sector de Bizkaia (OTSB 2015, 2017, 2019). La excepción es la investigación realizada por el Observatorio del Tercer Sector de Bizkaia de 2011 y actualizado en 2015 y 2017 (OTSB, 2015, 2017) sobre el Tercer Sector Social de Vizcaya, Cataluña y España, si bien los resultados se centran en los aspectos compartidos más que en los aspectos diferenciales del TSAS en dichas regiones desde una perspectiva comparada como la que se plantea en el tercer apartado de este texto.

A pesar del esfuerzo realizado en estos trabajos internacionales y regionales y en otras investigaciones comparativas previas para agrupar modelos de TS (Sarasa, 1995; Salamon y Anheier, 1998; Salamon et al, 2001; Evers and Laville, 2004; Monzón y Chaves, 2012), estas tipologías no dejan de ser una cierta simplificación de la realidad establecida a partir de ciertas similitudes en el concepto de TS, en su génesis sociohistórica o en su desarrollo dentro de diferentes regímenes de Estado de Bienestar. En particular, destacaríamos las siguientes limitaciones: 
En primer lugar, estas tipologías tienden a establecerse sobre todo en función de su relación con el sector público y, aunque está relación es muy relevante, en realidad no agota los factores explicativos diferenciales del desarrollo del TS en diferentes territorios. Eso pone de manifiesto que todavía hoy la investigación social sobre la sociedad civil y el TS no tiene el peso ni la importancia que se acumula en el análisis del Estado de Bienestar, del que suele ser un apéndice analítico (Rodríguez Cabrero y Marbán Gallego, 2015).

En segundo lugar, el establecimiento de tipologías o modelos de TS también requiere partir de un concepto consensuado y de una clasificación común. Este proceso se ve obstaculizado fundamentalmente por dos tipos de barreras: una barrera ideológica relacionada con el conjunto de valores diversos que abarca el Tercer Sector (espacio de libertad de expresión, contrapoder o socio del Estado, excusa para desmantelar el Estado de Bienestar, espacio de beneficencia o de compromiso...) con muchas connotaciones que hacen que el concepto de TS sea apropiado, interpretado, o acomodado ideológicamente de manera diferente por movimientos sociales y políticos progresistas o conservadores (Salamon and Sokolowski, 2018a). La segunda, una barrera operativa asociada a las tradicionales dificultades para encontrar una definición consensuada y una clasificación común de TS que pueda trasladarse a la comparación sistemática internacional dentro del marco de Sistema de Cuentas Nacionales ${ }^{3}$. Esto es especialmente complejo en lo que se refiere a las entidades de las Empresas Sociales y a la Economía Social por la dificultad añadida de distinguirlas operativamente de las empresas con ánimo de lucro (Salamon and Sokolowski, 2018b).

Por último, en la últimas décadas estamos asistiendo a procesos cada vez más complejos, entrópicos y globales que afectan a la desorganización y reorganización del welfare mix (Bode, 2006) (globalización económica, mercantilización, crisis económicas y políticas de consolidación fiscal, pandemias, desarrollo errático del Modelo Social Europeo, orientación de los Estados de Bienestar europeos hacia modelos descentralizados y de gestión multinivel de las políticas sociales públicas...) cuyo resultado es la mimetización y convergencia en una serie de tendencias comunes en el TS de los diferentes países, moduladas por la especificidad de la senda nacional de cada país, que van desdibujando la existencia de posibles modelos de TS. En particular destacaríamos las siguientes tendencias comunes en el TS europeo:

a) La extensión de la cooperación económica en la prestación de servicios entre el TS y la administración pública y la presión de las OTS por mantener sus estructuras y aumentar sus ingresos por prestación de servicios en un entorno cada vez más competitivo

3. El anterior Sistema de Cuentas Nacionales no cubría gran parte del trabajo voluntario ni informaba por separado sobre las instituciones sin fin de lucro, ya que la mayoría de los datos se fusionaban con datos sobre otros sectores. Este sistema se ha revisado, incluso se ha elaborado un nuevo manual de "Cuentas Satélite sobre las instituciones sin ánimo de lucro y afines y el voluntariado" que pretende superar estas limitaciones (disponible en https://bit.ly/3yKubzF; https://bit.ly/3jMH3kF) En este manual se refina y amplía el concepto de Tercer Sector conciliando las corrientes del enfoque no lucrativo estadounidense y el de Economía Social europeo. Aunque cada vez más países se han sumado a este esfuerzo, todavía faltan muchos por incorporarse. En buena medida su resultado dependerá de la disponibilidad de series de datos estables para periodos comparables entre los países, y de que los organismos nacionales de estadística creen cuentas satélite específicas para las instituciones sin ánimo de lucro atendiendo al nuevo concepto ampliado de Tercer Sector (Einarsson and Wijkström, 2019). 
han propiciado la prevalencia de la función de prestación de servicios y una relativa pérdida de la intensidad de la función cívico-política (Rodríguez Cabrero y Marbán, 2015).

b) Esta prevalencia de la prestación de servicios también está muy relacionada con la tendencia hacia la parcial mercantilización del TS. Se trata de un fenómeno global (Maier, Meyer and Steinbereithner, 2016) al que, en el caso de Europa, han contribuido fundamentalmente dos factores: 1) la creciente competencia selectiva del TS con las empresas por los recursos públicos destinados a los servicios de bienestar, fomentada por los gobiernos nacionales fruto de las políticas de consolidación fiscal; 2) la política de liberalización de servicios de la Unión Europea y la orientación de la financiación con fondos europeos hacia las OTS más profesionalizadas y empresarializadas en su gestión. Esto ha favorecido el debilitamiento del principio de subsidiariedad en favor de una creciente mercantilización o apertura al mercado de la competencia por los servicios de bienestar. El énfasis puesto en la eficacia de gasto por encima de las implicaciones sociales (Riolfo,2020), la complejidad de los requisitos de acceso a estos recursos y la sobrecarga de gestión asociada, han propiciado que la mayor parte de estos recursos se haya destinado a las entidades grandes más profesionalizadas en la prestación de servicios en perjuicio de las más pequeñas y orientadas a la comunidad (Zimmer and Pahl, 2018).

c) El fortalecimiento de la capacidad institucional del TS en los ámbitos nacionales y europeo y de la cooperación o complementariedad, según los casos, con las administraciones públicas en la gestión de servicios públicos. Se trata de una tendencia común instalada en la mayoría de los países europeos (todavía en construcción en buena parte de los Países del Este) si bien se encuentra limitada por la actual preeminencia de las políticas económicas y sociales pro-mercado. El creciente interés de los gobiernos por colaborar con las OTS para que estas desempeñen funciones gubernamentales como la provisión de servicios financiados con fondos públicos (o "nonprofization" de los Estados de Bienestar, Salamon, 2015) es un fenómeno al que habrá que seguir prestando atención en el futuro, lo mismo que al proceso de "mercantilización transitiva de los EB" que podría producirse fruto de la siguiente secuencia de relaciones transitivas entre los tres sectores: mercantilización de las OTS- nonprofization de los Estados de Bienestar=mercantilización de los Estados Bienestar.

d) Desarrollo de las organizaciones de la Economía Social como impulsoras del crecimiento económico y de la innovación social al servicio de nuevas formas de producción, consumo y empleo sostenibles e inclusivos para los colectivos vulnerables. A tal desarrollo han contribuido, entre otros factores, dos factores. En primer lugar, su respuesta a la crisis económica, durante la cual actuaron como refugio o amortiguador del desempleo de colectivos con más dificultades de inserción sociolaboral debido a su menor exposición a activos financieros y a su mayor flexibilidad laboral y compromiso con la conservación del empleo (Monzón y Chaves, 2012). En segundo lugar, por el apoyo de programas europeos, especialmente el Fondo Social Europeo, que contribuyeron a 
estructurar al sector en organizaciones de segundo nivel tanto a escala europea como nacional (Monzón y Chaves, 2016).

e) Otra tendencia común es la adaptación continua del TS a la dinámica de descentralización de los Estados de Bienestar, ajustando su actividad al territorio regional y local, lo que supone nuevas formas de colaboración entre el Sector Público y las entidades sociales. Este desarrollo consolida formas de desarrollo pegadas al territorio y sus tradiciones. Ello no impide que el TS cree estilos comunes de acción a nivel nacional y formas de interlocución con el Estado central.

f) Finalmente, podemos destacar cómo el TS de los países europeos también está afrontando unos retos y obstáculos comunes relacionados con los siguientes aspectos: a) falta de financiación pública a las OTS e infrafinanciación del sector público; b) la captación de humanos por la baja remuneración de los empleados y las dificultades para reclutar voluntarios y directivos con formación en administración de empresas; y c) mayor burocracia para responder a las exigencias de control y fiscalización del sector público sobre la vida de las entidades sociales (Zimmer y Pahl, 20184).

\section{Encaje institucional y social del TSAS en el Estado autonómico. ¿modelos de TSAS regionales 0 factores diferenciales?}

En esta sección respondemos tentativamente a dos preguntas: ¿Existe un modelo estatal de TSAS?, ¿existen modelos autonómicos diferenciados de TSAS?. Este análisis tiene como base empírica la realización y explotación de 48 entrevistas en profundidad y 14 grupos focales realizados entre expertos, responsables de las administraciones públicas autonómicas, directivos y representantes de las organizaciones del TS en siete comunidades autónomas significativas (Andalucía, Castilla y León, Cataluña, Comunidad de Madrid, Comunidad Valenciana, Euskadi y Región de Murcia) entre los meses de abril y septiembre de 2019 y abril -mayo de 2021.

Avanzando la respuesta a las dos preguntas de manera conjunta cabe afirmar que ni existe un modelo estatal de TSAS ni modelos autonómicos diferenciados. Sí cabe afirmar que a nivel estatal se ha configurado un estilo común en cuanto a la misión e identidad del sector, la defensa de un marco de regulación general (logrado finalmente en 2015), en presentarse como un interlocutor único y en la necesidad de cooperar establemente con el sector público, ampliando dicha cooperación a la economía social y la empresa mercantil.

4. Se trata de obstáculos identificados por estos autores a partir de la realización de una encuesta on-line dirigida a expertos en políticas de bienestar y profesionales del Tercer Sector de ocho estados europeos. 
Sin embargo, la gran diversidad interna del sector en tradiciones culturales, tamaños organizativos y financieros, en campos de actividad y modos de intervención social, entre otros rasgos, impiden que este hipotético modelo responda a una sola lógica. Existe un "estilo común de acción" en el conjunto del TSAS, pero no como único actor que actúe con una sola lógica. Igualmente cabe afirmar, como trataremos de demostrar a continuación, que no existen modelos autonómicos de TSAS nítidamente diferenciados. Entre ellos existen "diferencias de grado o singularidades" que se enraízan en su historia social y en el modo de relacionarse con el Estado de Bienestar a partir de la década de los 90 del pasado siglo. Más que de modelos cabe hablar de tradiciones autonómicas y territoriales.

En suma, la tesis aquí sostenida es que solo puede hablarse de un modelo estatal en cuanto a "estilo" común de acción y de modelos autonómicos en cuanto a "tradiciones" diferenciadas. Por ello, destacamos la idea central de que más que de un modelo estatal/modelos autonómicos de TSAS es necesario configurar la combinación de un estilo común de acción con singularidades territoriales, lo que se corresponde con un sector social muy diverso, unido por los hilos transversales de la misión (desarrollo social) y la práctica común de atención personalizada a los colectivos vulnerables bajo la lógica del desarrollo de los derechos sociales para todos.

Esta primera aproximación requiere de no pocos matices en la medida, por ejemplo, en que los expertos y estudiosos tienden a destacar la dimensión común entre los sectores sociales autonómicos, mientras que los directivos de las entidades tienden a destacar sus diferencias. No es una contradicción. Ello responde al propio desarrollo del TSAS en España marcado por la tensión constante entre las fuerzas centrípetas que lo conducen hacia una lógica común universalista (defensa de derechos, promoción de la participación social, lucha contra la exclusión social) y las fuerzas centrífugas que lo conducen hacia una lógica de diferenciación (adaptación funcional a las CCAA, ajuste de la acción al territorio y seguimiento de la senda cultural e histórica propia).

Por todo ello, nuestra tesis es que la acomodación funcional del TSAS a los gobiernos autonómicos y territoriales en la gestión de servicios y programas de servicios sociales ha reforzado una diferenciación funcional del sector, pero no estructural. A nivel global, el TSAS ha mantenido, e incluso reforzado, una lógica o estilo común en cuanto a sus objetivos generales, valores y desarrollo del capital relacional. No obstante, esto se ha producido con un carácter desigual como demuestra el hecho de que este sector haya tenido que ahormar flexiblemente su amplísima diferenciación interna con el concurso de herramientas de cohesión interna como son plataformas, redes, confederaciones y planes conjunto de acción sectoriales.

Mediante este análisis profundizamos en la tesis sostenida en la sección anterior de que el TS europeo y, sobre todo, el de objeto social, ha combinado la creación de organizaciones paraguas y plataformas de los diferentes sectores de actividad para promover una cierta misión común y un refuerzo de su cohesión interna, con la colaboración institucional y económica con los gobiernos territoriales, que son los que gestionan directamente las políticas sociales. Esta última colaboración se ha reforzado además -mediante un desarrollo de la economía social para asumir en las mejores condiciones financieras posibles la apertura de la provisión de servicios a la empresa mercantil. A nivel estatal o nacional el TS busca visibilidad social, mejora de 
su capital social y reforzamiento institucional. No es un modelo, es un modo de hacer, en parte defensivo y en parte proactivo. A nivel territorial, en cualquiera de sus niveles, el TS es un colaborador en la gestión de las políticas sociales, un objetivo que está mediado por las tradiciones locales y por los constreñimientos de una provisión de servicios sometidos crecientemente a la reducción de los presupuestos públicos y a la competencia con otros proveedores. Ahora bien, si la evidencia europea es indirecta, basada en fuentes secundarias, en el análisis del caso español confirmamos y profundizamos en esta tesis mediante la información directa recogida de una muestra de Comunidades Autónomas.

En base a esto definimos a continuación la naturaleza institucional de lo que denominamos como "estilo común" o marco estatal tentativo de TSAS en cuanto a misión, capital social e institucionalización. Después, consideramos las diferencias y rasgos comunes de una selección autonómica de TSAS, destacando sus singularidades o tradiciones ("identidades territoriales... con visión compartida", E8), es decir, el ajuste a los requerimientos de las políticas sociales territoriales a la vez que siguiendo la senda histórica de sus tradiciones culturales y organizativas. Finalmente, debatimos el potencial de desarrollo del TSAS (capacidad de respuesta personalizada a necesidades sociales y desarrollo del capital social) y las limitaciones que afronta para su consolidación como actor institucional en los años venideros (dualismo interno y problemas de sostenibilidad).

\subsection{La construcción institucional de un "estilo común de acción" del TSAS en España a lo largo de las cuatro últimas décadas}

El TSAS en España es un sector de actividad socioeconómica caracterizado por una gran diversidad interna en cuanto a tamaños organizativos y financieros, colectivos sociales objeto de acción y formas de incardinación en el territorio. Es un sector dual, con una cúpula de grandes organizaciones, una base amplísima de pequeñas entidades y un grupo pequeño de medianas organizaciones. Sus objetivos comunes son la defensa de los derechos sociales o actividad de sensibilización, sobre todo de los colectivos más vulnerables, el desarrollo de la participación social, incluidos los colectivos de personas afectadas, y la prestación de servicios, si fuera necesario, para cubrir fallos del Estado o dar respuestas innovadoras. Funciones complejas cuya conciliación supone asumir tensiones y contradicciones. Su objetivo es "mejorar las condiciones de vida de la gente... (en base a) una visión compartida" (E8) o creación de un "marco de referencia, de discurso, de relato" (E6). Su "diferencia fundamental es que ofrece, aparte del voluntariado, una concepción del trabajo de proximidad...ese es el gran activo del tercer sector" (E6).

En el Cuadro 1 representamos tentativamente los ejes que componen el desarrollo del TSAS en España a lo largo de las últimas décadas. El sector de objeto social ha contribuido de manera propia al desarrollo de los derechos sociales en España en colaboración con las Administraciones Públicas (AAPP) y otros actores de la sociedad civil organizada (asociaciones, fundaciones, cooperativas y empresas sociales) y parcialmente organizada (movimientos sociales y prácti- 
cas informales de solidaridad y ayuda mutua). Esto ha supuesto que este objetivo estratégico se haya tenido que acomodar funcionalmente a las políticas públicas de las que depende en parte en términos de regulación y financiación. De ahí que hablemos de acomodación funcional del TSAS a las políticas públicas. Una acomodación que también, en sentido inverso, requiere una adaptación de las AAPP a las características territoriales y organizativas del TSAS. Estamos ante una complementariedad desigual, sobre todo cuando hablamos de pequeñas organizaciones y de colaboración relativamente simétrica en el caso de las entidades singulares (Caritas, Cruz Roja y ONCE), grandes entidades y plataformas sectoriales ${ }^{5}$ y generales ${ }^{6}$.

La cooperación estable del TSAS con las AAPP ha venido de la mano de la prestación de servicios sociales y gestión de programas de bienestar, si bien el sector público también ha introducido progresivamente una lógica competitiva bajo la presión de segmentos del mercado que han entrado selectivamente en nichos rentables de actividad (como es el caso del sector de atención de la dependencia). Esta cooperación ha dado paso a alianzas formales entre ambos actores reflejadas en estrategias nacionales generales (inclusión social) o sectoriales (discapacidad o comunidad gitana) y en la apertura del sector a alianzas y acuerdos de cooperación con la economía social e, incluso, con la economía mercantil.

El crecimiento del TSAS, en base a la prestación de servicios y gestión de programas, ha exigido una profesionalización y racionalización de sus actividades que a veces choca, retórica y prácticamente, con los objetivos de reivindicación de derechos y de promoción de la participación social. Para canalizar esta doble actividad el TSAS ha acometido dos procesos de cambio: promover el Diálogo civil (nivel cívico-político) y Mesas de trabajo (nivel operativo) de encuentro con las AAPP donde negociar acuerdos estables de colaboración y canalizar las demandas de las entidades sociales. En segundo lugar, reforzando la presencia del sector social mediante una eficaz articulación interna de triple naturaleza: representativa (plataformas nacionales y sectoriales), operativa (trabajo conjunto, creación de redes estables de cooperación interna, creación de economías de escala) y de comunicación (para lograr una mayor visibilidad social de su actividad, siendo esta última uno de sus principales déficits).

El TSAS asume como una realidad inevitable normalizada la tensión permanente entre el objetivo de mantener su misión (desarrollo de los derechos sociales) y el imperativo de lograr su sostenibilidad institucional, financiera y organizativa. Ambos objetivos son compatibles, pero entre ellos se producen diferencias, tensiones y conflictos que varían dependiendo del tamaño organizativo, del sector de actividad y del entorno social e institucional. En las entidades en las que predomina la prestación de servicios, la lógica de la sostenibilidad económica y de la rentabilidad tiene un peso práctico superior en comparación al de aquellas otras cuyo objetivo fundamental es la sensibilización y abogacía social, en las que predomina la lógica de la promoción social.

La extensión e intensidad de las funciones básicas de las entidades sociales depende de su historia, lugar en el mapa territorial y organizativo y de la influencia de las políticas públicas. En el proceso de desarrollo del TSAS esta tensión ha dado lugar a una estructuración perma-

5. Por ejemplo, CERMI, CEOMA, UDP.

6. EAPN, PTS, POAS.

CIRIEC-España, Revista de Economía Pública, Social y Cooperativa I.S.S.N.: 0213-8093

№103/2021, pp. 9-41 
nente para adaptar sus funciones a las condiciones sociales, económicas y políticas en que tiene lugar su actividad. El TSAS no ha dejado de crecer y adaptarse al desarrollo de las políticas públicas al mismo tiempo que plantea sus propias iniciativas. Es un sector vivo en el que nacen y mueren organizaciones a gran ritmo dentro de una senda histórica de atomización y dualización interna que sigue caracterizando al sector desde hace décadas.

Los cambios en la estructura social y laboral, el impacto social de las crisis económicas en las condiciones de vida de la población vulnerable y el Estado de Bienestar multinivel, constituyen las tres variables que, entreveradas, condicionan el desarrollo de las entidades sociales. El conjunto del TSAS se ha adaptado como actor social a los cambios sociales conciliando sus diferentes objetivos de manera desigual. Y con ello ha creado un estilo común de acción caracterizado por tres rasgos: fortalecimiento institucional de la interlocución social, liderado por las grandes organizaciones y plataformas; reforzamiento del trabajo conjunto mediante la creación de redes y formas internas de colaboración (formación, centrales de compra, concurso conjunto en proyectos y licitaciones); y apertura a la colaboración con otros actores sociales y económicos para garantizar su sostenibilidad.

\section{Cuadro 1. El TSAS: desarrollo social y acomodación funcional}

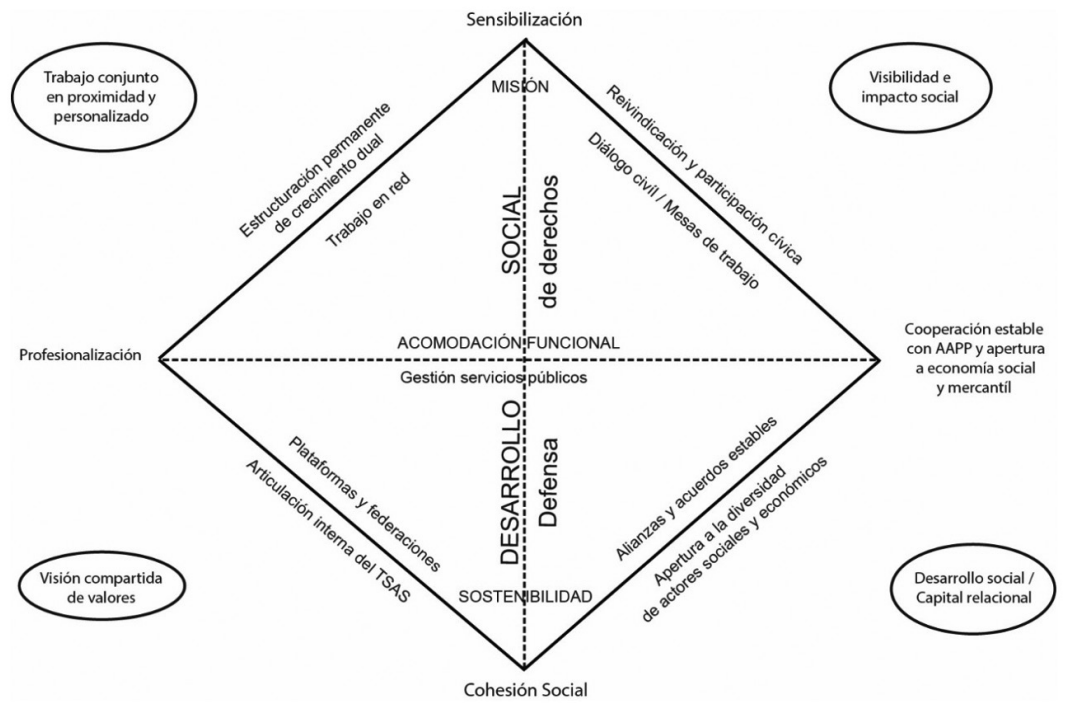

Fuente: Elaboración propia.

Estos rasgos definen lo que denominamos como un "estilo común de acción". Por estilo común de acción entendemos la conjunción de varias transversalidades: misión e identidad compartida, trabajo en común y en proximidad, proactividad e innovación e interlocución so- 
cial con capacidad de mediación en un entorno inevitable de acomodación a la hegemonía del sector público en la regulación y financiación del TSAS. Sin embargo, no puede hablarse de un modelo de TSAS dada la diversidad interna del sector y que cada ámbito sectorial tiene su propia dinámica y, si cabe, su propio modelo de intervención social como consecuencia de la necesaria adecuación a las demandas y necesidades territoriales.

Este estilo común, enfatizado en las entrevistas y grupos focales, cuenta con un amplio consenso entre los directivos y directivas de las entidades sociales, en parte como evidencia compartida y, en parte, por la necesidad del TSAS de crear espacios comunes de debate, moderar la fragmentación territorial en la que tiene lugar su actividad, fortalecer su misión y forjar modos de interlocución con el Estado que den coherencia a su función social.

\subsection{Singularidades territoriales más que modelos específicos}

Sostenemos aquí, en base a la evidencia cualitativa, que no hay modelos territoriales específicos de TSAS. Así lo refieren los directivos y expertos consultados casi con unanimidad. Existen vías territoriales o autonómicas de desarrollo con su historia social propia y modos de encaje diferente en la sociedad civil y formas variadas de colaboración con las AAPP. Ello es así porque, el TSAS es "muy grande, muy heterogéneo y muy atomizado" (E13) "muchas (organizaciones) muy pequeñas, muy dispersas y poco unidas" (E14), pero con una "actuación personalizada, el cuidado del detalle" (E11).

La diversidad y fragmentación del sector social es el punto de partida incuestionable. Como consecuencia, cada TSAS autonómico tiene su propia historia y dinámica de desarrollo, pero no hasta el punto de que pueda hablarse de modelos coherentes. En cada territorio reina la diversidad en el objeto social, en los tamaños organizativos y en los modos de cooperación con el sector público, la sociedad civil organizada, la economía social y el mercado. Así, el TSAS de Euskadi se apoya en una sólida sociedad civil y en una colaboración estrecha con el sector público, aunque no exclusiva en cuanto que también favorece la apertura a la contratación con el sector mercantil. El TSAS de Castilla y León también se caracteriza por una estrecha y larga colaboración con el sector público, mutuamente conveniente en un territorio extenso y vaciado; existe una colaboración institucional estable, si bien el sector público marca las condiciones de la colaboración. El TSAS de Cataluña tiene como especificidad un voluminoso y asentado voluntariado social que convive con una relación público-privada en la que el TSAS tiene delimitado en la práctica su ámbito de acción. El TSAS de Andalucía se caracteriza por una gran dependencia financiera del sector público que, de alguna manera, marca el ritmo de su crecimiento y una sociedad civil menos densa que en otros territorios; en cierto modo, el TSAS debe parte de su expansión al apoyo permanente del sector público autonómico Finalmente, Madrid, es la sede de las grandes entidades y plataformas del TSAS. A la vez el sector social de la región se caracteriza por un desarrollo desigual en el que se producen tensiones inevitables entre la tendencia del sector público a la integración funcional del sector social vía 
gestión de servicios y el objetivo de muchas entidades de destacar su papel de sensibilización y reivindicación de derechos y de ganar apoyo en la sociedad civil. Seguramente esta tensión es más evidente en el caso de Madrid que en otras Comunidades Autónomas.

Las especificidades y estilos territoriales son de grado y al mismo tiempo comparten rasgos comunes, si bien de manera desigual, a lo largo del territorio del Estado. Aunque aquí analizamos una muestra significativa de CCAA, cabe enfatizar que existe una transversalidad compartida en cuanto a los rasgos que definen al conjunto del sector social, entre los que destacamos los cuatro siguientes:

1. El TSAS, sea de la CCAA que sea, está integrado dentro de sistemas mixtos de servicios sociales. La totalidad de las leyes de servicios sociales reconocen el papel del TSAS como actor prestador de servicios y de gestor de programas públicos. También se ha reforzado la colaboración con los sistemas de educación, sanidad y vivienda ya que muchas de las necesidades a las que da respuesta el sector social son multidimensionales y, por tanto, existen entidades sociales fronterizas. Esta realidad ha supuesto que la colaboración con el sector público se haya institucionalizado y consolidado a lo largo de las últimas décadas por conveniencia mutua, tanto financiera como operativa e, incluso, estratégica (que se materializa en la participación del TSAS en estrategias nacionales de inclusión social, discapacidad, población gitana e igualdad de género). La colaboración entre el TSAS y el sector público no puede reducirse a una colaboración económica, pero sin duda alguna el modelo mixto de producción de servicios sociales, y en general, de servicios públicos, ha reforzado esta dimensión. El TSAS ha tratado de que la colaboración sea amplia y estable a través de convenios y acuerdos, ampliada al desarrollo del diálogo civil y a la participación en el diseño de las estrategias y políticas de lucha contra la exclusión social. La colaboración, por lo tanto, no solo es económica sino también institucional. Ahora bien, la dimensión económica ha ganado en importancia, tanto por la presencia selectiva de la empresa mercantil en la gestión de servicios, como por la diversidad de formas que esta ha adoptado. El TSAS, en conjunto, favorece fórmulas estables de colaboración económica tratando en cierto modo de "blindar" una colaboración económica estable; y al mismo tiempo apoyando la inclusión de "cláusulas sociales" en los contratos que favorezcan a las entidades sociales por razón del colectivo al que se dirigen o por los efectos previstos en cuanto a mejora de las condiciones de vida de los colectivos vulnerables. La combinación de opciones de colaboración económica es diversa en las distintas CCAA. Todo depende del grado de confianza institucional entre el sector social y el TSAS y de los encajes de regulación existentes.

La crisis de la Obra Social de las Cajas de Ahorro, con la excepción de La Caixa, y la creación de las fundaciones bancarias, ha supuesto no sólo una reducción de ingresos que eran relativamente estables, sino también de formas de colaboración que se denominan "comerciales". Una nueva dinámica en la que los márgenes de autonomía de las entidades sociales se reducen en pro de los objetivos del financiador. En general, el ajuste a la baja de los ingresos, públicos y privados, parece que ha obligado a aplicar la lógica "de hacer más con menos" generando la percepción de que "parece que como trabajamos con pobres, todo vale y tenemos que vivir como ellos" (E3). El TSAS ha tenido que recurrir cada vez más a los recursos propios, Aunque, sin duda, ello tiene sus límites. De ahí el discurso reiterado de los directivos sociales de fortalecer 
la colaboración con el sector público como modo de asegurar una cierta estabilidad en la captación de ingresos a medio plazo.

2. Un segundo común denominador del TSAS en las diferentes CCAA es el "crecimiento de organizaciones, la profesionalización" (E36), exigido por la dinámica de la gestión pública, por la competencia del sector mercantil y por el propio convencimiento de que el sector social gestiona servicios y programas en un entorno complejo. La expansión del sector social durante el período 1990-2010 ha venido acompañada de crisis económicas y sociales y crecimientos económicos que han incrementado y reducido sus ingresos a modo de "acordeón". No así sus gastos, que han tendido a crecer para dar respuesta a las demandas y necesidades sociales. Todo ello manteniendo, en el conjunto del sector social, un equilibrio en las cuentas, al mismo tiempo que la precariedad financiera ha sido característica en más de un tercio de las entidades sociales. Paradigmática por su impacto ha sido la crisis de 2008 que supuso que entre ese año y 2014 los recursos propios fueran una fuente de financiación creciente para hacer frente a los efectos sociales de la crisis, cambio que prácticamente ha llegado hasta la antesala de la crisis de la COVID-19.

La crisis de 2008 supuso aplicar una amplia racionalización de medidas en el TSAS en forma de ajustes de tamaño, disolución de entidades y, sobre todo, búsqueda acelerada de nuevas formas de trabajo conjunto para generar economías de escala y ahorrar costes organizativos. El tamaño de las organizaciones ha decrecido en términos de ingresos durante la pasada década. Como esto no ha supuesto ajustes drásticos de empleo ni reducción de actividad, para lograr un equilibrio financiero ha sido necesario aplicar medidas de devaluación interna salarial y la utilización de los recursos propios. Finalmente, hay que destacar que la profesionalización ha supuesto la mejora de las herramientas de formación, auditoría interna y externa, rendición de cuentas y transparencia, exigidas en los casos de reconocimiento de entidades de utilidad pública, pero también por la necesidad de hacer visibles la actividad realizada y hacer públicas las cuentas y balances. Una mejora que sólo alcanza a una parte de las organizaciones, las que tienen mayor capacidad económica y organizativa.

3. ¿Ha supuesto esta racionalización, además de los cambios en las fuentes de financiación, un efecto ideológico o "reorientación ideológica" (E36) del TSAS? La respuesta general de expertos y directivos es afirmativa parcialmente, sobre todo en las entidades sociales relacionadas con la provisión de servicios o más próximas a la actividad mercantil. Se ha producido lo que se denomina como relativa y selectiva "empresarialización" de la actividad de provisión de servicios, estimulada por la irrupción del sector mercantil en la prestación de servicios. Sin embargo, el sector social no parece haber asumido una lógica defensiva o reactiva, que puede considerarse minoritaria ("miedo a perder una parte de su idiosincrasia", E37), sino adaptativa de la misión y valores a la cambiante realidad. El pragmatismo se ha impuesto relativamente en el ámbito de la prestación de servicios, cuya gestión requiere de cierta estabilidad financiera. En las entidades ancladas en actividades de sensibilización y promoción social el debate ideológico se sitúa en cómo renovar la misión del sector social y en cómo impulsar el desarrollo de los derechos sociales. Una parte importante de las entidades combina la prestación de servicios con las funciones de abogacía social y desarrollo de la participación cívica. En este 
caso, la gestión rentable de servicios se articula con el objetivo estratégico de desarrollo del capital social en su más amplio sentido; importa más la estabilidad de las alianzas y acuerdos con los diferentes actores sociales que la propia prestación de servicios, que se considera instrumental. Dicho de otro modo, el desarrollo del capital social o refuerzo de la cohesión social interna y externa es el objetivo por excelencia que, además, se considera que deviene en mejora de la sostenibilidad del TSAS.

4. La ampliación de la regulación del TSAS es un objetivo dirigido a potenciar la interlocución y el reconocimiento estable por parte del sector público. Las entidades sociales dan una gran importancia al logro de este objetivo. Dicha regulación varía entre CCAA, pero los medios son los mismos. En primer lugar, el desarrollo de leyes del tercer sector a partir de la ley del tercer sector de 2015. Es el caso de Euskadi que ha aprobado una ley del tercer sector en 2016 o de CCAA que se han comprometido a aprobarlas (Cataluña y Castilla y León). En segundo lugar, las leyes de servicios sociales de todas las CCAA reconocen el rol del TSAS como colaborador del sector público en el desarrollo de las políticas sociales, tanto en la gestión de servicios, como en el diseño de políticas y estrategias (bajo la forma de consulta). Es el caso de la ley de servicios sociales de Andalucía de 2016 o de Castilla y León de 2010. El tercer instrumento son las Mesas de Diálogo entre las AAPP y el TSAS o mesas de Diálogo Civil. Son mesas de debate y consulta, experimentadas por los gestores sociales de muy diferentes modos, compatibles entre sí: como vía de legitimación de las políticas públicas, como espacio para el intercambio de ideas y proyectos sociales, como vía de anticipación de acuerdos, como modo de canalización de las demandas del sector social, entre otras posibles. La valoración de su eficacia varía entre los diferentes sectores sociales territoriales y, en general, tienen una valoración dual, más negativa por parte de las pequeñas entidades y más positiva por parte de las grandes entidades o plataformas y federaciones. Estas mesas también se constituyen dentro del propio sector social como ámbito interno, sectorial o general, de debate e intercambio de ideas, un espacio de contraste entre fines y medios. Finalmente, hay que destacar las leyes de voluntariado de las CCAA que, como desarrollo de las leyes estatales de 1996 y 2015, reconocen y promueven, entre otros, el voluntariado social. Esta última regulación no se destaca especialmente en los discursos de gestores y expertos a pesar de que este sector supone una parte importante de los recursos humanos del TSAS.

\subsection{Lograr la sostenibilidad de las entidades sociales siendo socialmente útiles y visibles}

Los discursos y reflexiones de gestores, expertos y participantes en las entrevistas y en los grupos focales tienden a trascender el dualismo discursivo de gestión de servicios versus sensibilización y participación social, en favor de un ámbito de reflexión en el que integrar ambos objetivos. Todo indica que la idea de sostenibilidad es la que puede articular estos objetivos y conciliar relativamente las tensiones que genera su logro. Para ello, se requiere salir hasta donde sea posible de la lógica de la acomodación funcional y entrar en una lógica de creatividad y 
apertura social ("Estamos un poco acomodados, igual hay que ser más creativos", GD01). Cabe descomponer analíticamente el objetivo estratégico de sostenibilidad, como modo de conciliación de la misión del sector con su diversidad territorial, en cuatro ejes complementarios.

1. Por una parte, la sostenibilidad económico-financiera, cuyo objetivo es lograr una estabilidad relativa en la captación de los ingresos mediante una pluralidad de fuentes de financiación relativamente estables. La subvención, como técnica de fomento, es una de ellas, pero los convenios y conciertos suponen una mayor estabilidad. La importancia creciente de los contratos, a los que también concurre el sector mercantil, y la debilidad de las cláusulas sociales, suponen un menor margen de maniobra en la captación de ingresos en ámbitos de actividad que generan rentabilidad. La condicionalidad de otras fuentes de financiación (RSC y fundaciones bancarias) resta autonomía a la acción de las entidades sociales. Por otra parte, es necesario mejorar la capacidad de adaptación del TSAS a la situación económica, lo que supondría "capacidad de crecer, menguar, crecer, menguar, crecer, menguar" (E13), en línea con el desarrollo del sector durante el período 2000-2018. La descentralización del 0,7\% del IRPF a las CCAA ha supuesto ventajas como son el acceso de las pequeñas entidades a las subvenciones, pero también el riesgo de pérdida de capacidad de cohesión a nivel estatal ("riesgo de que se diluya el fin del interés general o interés social", E10). La colaboración con la economía social es otra de las vías que pueden reforzar la sostenibilidad económica. Es el caso del sector social de Madrid, que junto a la apuesta por el "trabajo conjunto" (E7) parece haber optado por el "acercamiento y confluencia" (E8) con la economía social. Pero que, al mismo tiempo, en las diferentes Comunidades Autónomas, recela de "formas híbridas, que se mueven entre la empresa y sin ánimo de lucro, (que) están deseando copar cada vez más mercado" (E34). Las posiciones en este aspecto no son coincidentes en los discursos de las diferentes Comunidades Autónomas. Por un lado, el sector se decanta en favor de fórmulas de colaboración basadas en el convenio y en los contratos con cláusulas sociales ya que "no defendemos que la regla sea el mercado, ni el precio, sino la calidad de la ecuación, la solidaridad, la eficiencia, la responsabilidad" (E16). Pero al mismo tiempo, desde la propia administración regional, no en todas, se favorecen formas de concurrencia que evitan lo que se denomina como "público cautivo y unas subvenciones y convenios cautivos" (E17). La competencia abierta por la gestión de servicios sociales hace inevitables las tensiones en el seno del TSAS y entre este y otros actores económicos.

2. La sostenibilidad organizativa es el segundo vector señalado por las personas entrevistadas y por los grupos focales. No todas las entidades sociales pueden lograr la estabilidad en sus ingresos y, por ello, dependen en parte del "trabajo en red, en red y coordinado de entidades...apoyos, fusiones" (GD04). La mención de las fusiones es significativa ya que su utilización podría optimizar el tamaño organizativo dentro de un mismo sector de actividad. Pero esta última opción tiene un cierto carácter de tabú o uso excepcional. La contratación conjunta de actividades (formación, compras, entre otras) y la creación de consorcios ad hoc para licitar en concursos, son ejemplos concretos del trabajo en red.

3. La sostenibilidad institucional es seguramente el eje más importante señalado por gestores y expertos. Es la capacidad de crear cohesión social interna y mejorar la capacidad de interlocución con otros actores sociales y, si es posible, alianzas estables con las AAPP. La ar- 
ticulación interna del sector se ha demostrado que es una de las fuentes de capital social más importante. Este objetivo no es siempre posible por los "vetos" (E 1) cruzados que a veces se producen entre entidades y el impacto de los hiperliderazgos. Una articulación que no puede ser sólo desde arriba, sino que tiene que ser transversal al conjunto del TSAS, combinando lo local con lo estatal (federaciones y estructuras nacionales). La capacidad de interlocución se considera una herramienta para la transmisión de las demandas de las entidades y la estabilidad de la consulta de políticas sociales y planes estratégicos sectoriales. La actual colaboración entre el TSAS y las AAPP tiene mucho de instrumental y poco de reflexiva ("no hay reflexión en común...no hablamos de temas comunes", E3). La asimetría en la colaboración entre el TSAS y las AAPP, a la que antes nos hemos referido, variable entre subsectores y tamaños organizativos, sigue siendo una de las limitaciones para forjar alianzas estables. Todo depende del "ecosistema de colaboración" (E37) que exista en cada territorio y en el desequilibrio que pueda haber entre la función prestadora de servicios y la de "prevención y promoción de derechos" (E36).

4. Finalmente, hay que destacar la sostenibilidad social, definida como la capacidad del TSAS de "crear redes de apoyo de la sociedad, de la calle...tener a la sociedad de verdad detrás" (E11). Dar espacio a la ciudadanía, tanto a las personas afectadas como a la población en general, se considera esencial para la sustentación del TSAS y la puesta en marcha de iniciativas innovadoras en los diferentes campos de actividad. Incluso se habla de refundación del sector social mejorando sus conexiones con la sociedad civil. La crisis social y política de la primera parte de la década pasada ha generado un amplio debate en el TSAS sobre la necesidad de reforzar los vínculos con la sociedad civil. A lo largo de todos los debates y entrevistas aparece de manera latente y explícita este desiderátum de no perder la conexión con la sociedad civil no organizada. La necesaria profesionalización y modernización del TSAS no puede impedir que las entidades sociales estén conectadas con las diferentes formas en que se manifiesta la sociedad civil, desde los movimientos sociales hasta los desarrollos de economía solidaria que han aparecido a lo largo de las dos últimas décadas.

\section{Conclusiones}

Este artículo responde a la pregunta de investigación de si existen modelos territoriales de TSAS en España o simplemente estamos ante singularidades o diferencias de grado. De existir modelos territoriales estaríamos hablando de la consolidación de una fragmentación de modelos yuxtapuestos entre sí, difícilmente compatibles con un modelo estatal de TSAS o con la creación de un marco común de pensamiento y acción. Si, por el contrario, hablamos de singularidades nos estamos refiriendo a tradiciones o sendas histórico-culturales que, al mismo tiempo, comparten a nivel estatal una misión, un estilo común de acción y modos de cooperación entre las entidades sociales y de colaboración con el sector público. La tesis aquí sostenida, en base a la evidencia de grupos focales y entrevistas en profundidad realizadas en una muestra de Comunidades Autónomas, es que el TSAS ha construido a lo largo de las 
últimas décadas un estilo común de pensamiento y acción compatible con las diferentes singularidades territoriales. Para demostrar esta tesis hemos definido, en primer lugar, la naturaleza y ámbito del TSAS, en cuyo desarrollo ya está implícita la tesis aquí defendida. Después hemos revisado la literatura internacional en relación con los modelos de TSAS desde la doble perspectiva de relación con el sector público y su incardinación en el territorio. Finalmente, hemos desarrollo la tesis antes mencionada considerando la coexistencia de un estilo común a nivel estatal con las diferentes singularidades territoriales. Destacamos a continuación las principales conclusiones:

No puede comprenderse la tesis aquí sostenida si no consideramos previamente la naturaleza y evolución del TSAS a lo largo de las últimas décadas. Aunque sus raíces históricas son profundas, es suficiente con referirnos al período democrático. A lo largo de los últimos cuarenta años el TSAS ha tenido una gran expansión debido a la reconstrucción de la sociedad civil, la multiplicación de las demandas sociales, a las que el Estado no siempre llega, y a la progresiva conformación de un modelo mixto de bienestar, en la senda de la mayoría de los países de la UE y bajo el propio impulso de la Comisión Europea. El TSAS se ha expandido en una primera fase de, aproximadamente, veinte años de una manera dual: un pequeño grupo de grandes organizaciones en un espacio de miles de pequeñas organizaciones, muchas de las cuales desaparecen con el tiempo por falta de recursos. La descentralización de las políticas sociales, la adecuación de las entidades sociales al territorio y la dificultad de dar respuestas a necesidades complejas, condujeron desde finales del siglo pasado hasta la actualidad a afrontar procesos de racionalización, acelerados a su vez por el impacto de la crisis de 2008 y la apertura de la provisión de los servicios sociales a la empresa mercantil. La respuesta general fue reforzar la cooperación con las AAPP e intensificar la colaboración dentro de cada sector de entidades sociales y entre el conjunto de las mismas a través de confederaciones y plataformas sectoriales y generales y diferentes formas de trabajo conjunto, al mismo tiempo que mejorando su capacidad de gestión de programas y recursos humanos y financieros. El impulso del diálogo civil y la cooperación con la economía social han sido también dos herramientas en pro de la sostenibilidad del TSAS, incluso una apertura selectiva hacia la empresa mercantil. La combinación por parte del TSAS del doble objetivo de reforzar la territorialización de su acción y de crear modos a nivel estatal que refuercen su misión, capacidad institucional y visibilidad social, son dos vías complementarias de acción que han contribuido a forjar el modelo que aquí señalamos de estilo común y singularidad territorial.

Lo que podríamos denominar de manera aproximada como modelo español de TSAS se sitúa en la senda de experiencia de los países de nuestro entorno. Es decir, el TSAS en los diferentes regímenes de bienestar de la UE ha seguido la doble senda de la territorialización al compás de la descentralización del Estado de Bienestar y, al mismo tiempo, ha creado plataformas y órganos de representación y colaboración a nivel estatal con el fin de reforzar su papel institucional. Una doble combinación que, sobre todo, tiene lugar en los países que cuentan con un mayor grado de descentralización (caso de Alemania y Bélgica en el nivel regional y los países nórdicos y anglosajones a nivel municipal). Tal como hemos señalado en la sección segunda, el genérico modelo europeo de TSAS combina el reforzamiento del capital social del 
TSAS a nivel de cada Estado nacional con la gestión en cada territorio de su actividad en cooperación con el Estado y otros actores sociales y económicos. Es decir, se combina el objetivo de lograr la máxima capacidad institucional con el objetivo de máxima adecuación a las necesidades de cada territorio.

Esta senda es la que ha seguido el desarrollo del TSAS en España, con su propia historia y peculiaridades. Existe una amplia coincidencia entre directivos y expertos en que a lo largo de las últimas décadas se ha configurado un TSAS que progresivamente se ha descentralizado para ajustarse al diseño de las políticas sociales. Con ello se ha reforzado en parte la cultura del TSAS de cada territorio, sus singularidades, adaptadas a los requerimientos y financiación de las políticas autonómicas. Pero al mismo tiempo, el TSAS ha tenido como guía estratégica implícita, a veces explicita, que su misión es la defensa de los derechos sociales, lo que trasciende el plano territorial y envía un mensaje de universalidad. Razón por la cual se ha visto comprometido a destacar la lógica de su identidad y valores compartidos, ampliar los espacios de colaboración en los diferentes sectores de actividad y reforzar su capacidad institucional como actor necesario en el desarrollo de las políticas sociales. Es lo que denominamos como creación o forja de un estilo común.

En base a esta doble caracterización, en la actualidad el TSAS afronta el reto de sus sostenibilidad financiera, organizativa, institucional y social. Objetivo que se despliega tanto en el nivel general, lo que denominamos como "estilo común", para ganar capacidad institucional, como en el nivel territorial, espacio este último del que procede el grueso de los recursos del sector y donde colaboran con el sector público en la gestión de programas y en el diseño de políticas. Este modelo dual seguramente continuará durante los próximos años mientras no se modifique el modelo de producción mixta de bienestar. Si incrementará o no la fragmentación territorial del TSAS será una cuestión para debatir y seguir analizando a medio plazo.

Contribución de cada autor/a: Vicente Marbán Gallego: Aportación teórica, elaboración y análisis de entrevistas y grupos focales, revisión bibliográfica; Gregorio Rodríguez Cabrero: Aportación teórica, revisión elaboración y análisis de entrevistas y grupos focales, revisión bibliográfica.

Financiación: Proyecto financiado por el Programa de I+D+i de excelencia del Ministerio de Economía Industria y Competitividad (RFA: CSO2017-85486-P)

\section{Bibliografía}

AGUIAR, F. \& PÉREZ YRUELA, M. (1995): “Aproximación al sector voluntario andaluz en el ámbito de los servicios sociales". En: Sarasa \& Moreno (eds.), El Estado del Bienestar en la Europa del Sur, CSIC, 215-238, Madrid.

BAREA, J. \& MONZÓN, J.L. (2002): Informe de Síntesis sobre la Economía Social en España, CIRIEC-España, Valencia. 
BEŽOVAN, G. (2016): "The role and impact of the Third Sector in transformative process: A comparison of post-socialist countries Slovenia, Czech Republic and Croatia", TSI Working Paper Series, No. 13, Seventh Framework Programme (grant agreement 613034), European Union, Third Sector Impact, Brussels.

BODE, I. (2006): "Disorganized welfare mixes: Voluntary agencies and new governance regimes", Western Europe, Journal of European Social Policy, 16, 346-359.

DOI: $10.1177 / 0958929706068273$.

BUENDÍA, L. (2012): Dinámica de crecimiento, distribución de la renta y movimiento obrero: el estado de bienestar sueco en una perspectiva de largo plazo, Tesis Doctoral, UCM, Madrid.

CABRA DE LUNA, M.A. \& LORENZO, R. (2005): “El Tercer Sector en España: ámbito, tamaño y perspectivas", Revista Española del Tercer Sector, 1, 95-134.

CASAD0, D. (2015): "Cambios y continuidades en el tercer sector de acción social", Revista Española del Tercer Sector, 30, 23-47.

CHAVES, R. \& MONZÓN, J.L. (2020): Libro Blanco de la Economía Social y del Tercer Sector en la Comunitat Valenciana, CIRIEC-España, Valencia.

CODINA, T. (Dir.) (2016): Baròmetre del Tercer Sector Social. Edició 2016. Informe de resultats, Barcelona, Taula d'entitats del tercer sector social de Catalunya. http://www.plataformatercersector.es/sites/default/files/informe_barometre_2016_maquetat_0.pdf

EINARSSON, T. \& WIJKSTRÖM, F. (2019): "Satellite Account on Nonprofit and Related Institutions and Volunteer Work, book review", Nonprofit Policy Forum, 10 (1), 1-5.

DOI: $10.1515 / \mathrm{npf}-2019-0011$.

ENJOLRAS, B., SALAMON, L., SIVESIND, K.H. \& ZIMMER, A. (2018): The Third Sector as a Renewable Resource for Europe, Cham: Palgrave Macmillan.

https://doi.org/10.1007/978-3-319-71473-8

EVERS, A. \& LAVILLE, J.L. (eds.) (2004): The Third Sector in Europe, Cheltenham and Northampton, Edward Elgar.

FRESNO, J.M. (2014): Cambios Sociales y Tercer Sector: Actuar en un Nuevo Contexto, Instituto para la calidad de las ONG (ICONG), Madrid.

FUNDACIÓN LUIS VIVES (2010): Anuario del Tercer Sector de Acción Social en España, Fundacion Luis Vives, Madrid.

FUNDACIÓN LUIS VIVES (2011): Modelos europeos en la evolución del Tercer Sector Social, FLV, Antares Consulting y Fundación Caja Madrid, Madrid. 
FUNDACIÓN LUIS VIVES (2012): Anuario del Tercer Sector de Acción Social en España, Fundacion Luis Vives, Madrid.

GARCÍA DELGADO, J.L. (Dir.) (2005): La economía social en España. Criterios y propuestas, Fundación ONCE, Madrid.

GONZÁLEZ, A. \& JARAÍZ, G. (2020): "Las políticas de inclusión social en Andalucía desde la perspectiva discursiva y lexicométrica. Un análisis comparativo del discurso técnicopolítico", EMPIRIA, Revista de Metodología de Ciencias Sociales, 45, 75-111. D0I/ empiria.43.2020.26305.

KENDALL, J., BROOKES, N. \& MOHAN, J. (2016): "The English third sector policy in 2015: An overview of perceived barriers to realizing impact potential, Summary of research findings for Work Package 5", TSI Policy Brief No. 3. http://thirdsectorimpact.eu/documentation/tsi-barriersbriefing- no-1-english-third-sector-policy-in-2015/

LORENDAHL, B. (1999): "Trabajo y bienestar a través de las organizaciones del Tercer Sector", CIRIEC-España, Revista de Economía Pública, Social y Cooperativa, 33, 9-27.

MAIER, F., MEYER, M. \& STEINBEREITHNER, M. (2016): "Nonprofit organizations becoming business-like: A systemic review", Nonprofit and voluntary sector quarterly, 45(1), 64-86. DOI: $10.1177 / 0899764014561796$.

MARBÁN, V. \& RODRÍGUEZ, G. (2013): “Sistemas mixtos de protección social. El tercer sector en la producción de bienestar", Presupuesto y Gasto Público, 71, 61-82.

MARBÁN, V., PÉREZ, M. \& RODRÍGUEZ, G. (2020): “Current challenges and prospective analysis of the Third Sector of Social Action (TSSA) in Spain", CIRIEC-España, Revista de Economía Pública, Social y Cooperativa, 98, 95-126. DOI: 107203/CIRIEC-E.98.15385.

MONTSERRAT, J. (2013): "El impacto de la crisis económica en las organizaciones del Tercer Sector de Acción Social”, Revista Española del Tercer Sector, 23, 77-97.

MONZÓN, J.L. \& CHAVES, R. (2012): La economía social en la Unión Europea, Bruselas: Comité Económico y Social Europeo (CESE) y CIRIEC.

DOI: http://dx.doi.org/10.2864/19566.

MONZÓN, J.L \& CHAVES, R. (2016): Evolución reciente de la economía social en la Unión Europea, Bruselas: Comité Económico y Social Europeo (CESE) y CIRIEC, Bruselas. https://www.eesc.europa.eu/sites/default/files/files/qe-04-17-875-es-n.pdf

OBSERVATORIO DEL TERCER SECTOR SOCIAL DE BIZKAIA (OTSB) (2015): Los diagnósticos de situación del Tercer Sector Social de Bizkaia, Catalunya y España. Retos compartidos, Observatorio del Tercer Sector de Bizkaia, Bilbao. 
OBSERVATORIO DEL TERCER SECTOR SOCIAL DE BIZKAIA (OTSB) (2017): El Tercer Sector Social en Euskadi, Catalunya y España: una mirada comparativa 2017, Bilbao: Observatorio del Tercer Sector de Bizkaia.

OBSERVATORIO DEL TERCER SECTOR DE BIZKAIA (OTSB) (2019): Libro Blanco del Tercer Sector Social de Euskadi 2019, Bilbao: Observatorio del Tercer Sector de Bizkaia.

PÉREZ DÍAZ, V. \& LÓPEZ NOVO, J.P. (2003): El Tercer Sector Social en España, Madrid: Ministerio de Trabajo y Asuntos Sociales.

PÉREZ YRUELA, M. (2019): “Panorámica del Tercer Sector en España durante la crisis”, Documento de trabajo 4.6. En VIII Informe Foessa. Madrid: FOESSA.

PÉREZ YRUELA, M. \& RODRÍGUEZ CABRERO, G. (2020): El Tercer Sector de Acción Social como actor estratégico de la sociedad civil en España, Documento de trabajo, Madrid: Fundación Botín.

PLATAFORMA DE ONG DE ACCIÓN SOCIAL (POAS) (2015): El Tercer Sector de acción Social en 2015. El impacto de la crisis, Madrid: POAS.

PLATAFORMA DE ONG DE ACCIÓN SOCIAL (POAS) (2020): El Tercer Sector de acción Social en España. Nuevo contexto, nuevos horizontes, Madrid: POAS.

RIOLFO, G. (2020): “The New Italian Benefit Corporation", European Business Organization Law Review 21, 279-317, D0I: https://doi.org/10.1007/s40804-019-00149-9.

RODRÍGUEZ CABRERO, G. (2003) (coord.): Las entidades voluntarias de acción social en Espa$\tilde{n} a$, Madrid: FOESSA.

RODRÍGUEZ CABRERO, G. (2013): “Crisis estructural y Tercer Sector de Acción Social”, Revista Española del Tercer Sector, 23, 17-40.

RODRíGUEZ CABRERO, G. (2020): "El Tercer Sector de Acción Social en España. Desarrollo reciente y retos de futuro", Anales de Derecho y Discapacidad, 5, 193-212.

RODRÍGUEZ CABRERO, G. \& MARBÁN GALLEGO, V. (2015): Análisis prospectivo sobre los retos actuales y futuros del Tercer Sector de Acción Social. Parte I: El Tercer Sector de Acción Social en el Contexto de la Unión Europea. Situación Actual y Tendencias de Futuro del TSAS en España. Madrid, POAS.

RUÍZ OLABUÉNAGA, I. (2000): El sector no lucrativo en España, Madrid: Fundación BBVA.

SALAMON, L. (2015): "Introduction: The nonprofitization of the welfare state", Voluntas, 26, 2147-2154. DOI: 10.1007/s11266-015-9638-3. 
SALAMON, L. \& ANHEIER, H. (1998): "Social Origins of Civil Society: explaining the Nonprofit Sector Cross-Nationally”, Voluntas, 9 (3), 213-249. DOI: 10.1023 / A: 1022058200985.

SALAMON, L., ANHEIER, H., LIST, R., TOEPLER, S. \& SOKOLOWSKI, S.W. (2001): La sociedad civil global: las dimensiones del sector no lucrativo: proyecto de estudio comparativo del sector no lucrativo de la Universidad Johns Hopkins, Madrid: Fundación BBVA.

SALAMON, L. \& SOKOLOWSKI, S.W. (2018a): "Beyond Nonprofits: In Search of the Third Sector". In Enjolras et al., Cham, Palgrave Macmillan, 7-48.

SALAMON, L. \& SOKOLOWSKI, S.W. (2018b): "The Size and Composition of the European Third Sector". In Enjolras et al., Cham, Palgrave Macmillan, 49-94.

SALAMON, L., SOKOLOWSKI, S.W. \& HADDOCK, M.A. (2017): Explaining civil society development: A social origins approach, Johns Hopkins University Press, Baltimore.

SARASA, S. (1995): "La Sociedad Civil en la Europa del Sur. Una perspectiva comparada de las relaciones entre Estado y Asociaciones Altruistas". En: Sarasa \& Moreno (eds.), El Estado del Bienestar en la Europa del Sur, CSIC, Madrid, 157-186.

SIVESIND, K.-H. \& SELLE, P. (2010): "Civil society in the Nordic countries: Between displacement and vitality". In: R. Alapuro \& H. Stenius (Eds.), Nordic associations in a European perspective, Nomos, Baden-Baden, 89-120.

SYSTEME (2015): El Tercer Sector de Acción Social en 2015: impacto de la crisis, POAS, Madrid.

ZIMMER, A. (1999): "Corporatism revisited - The legacy of history and the German nonprofit-sector", Voluntas, 10(1), 37-49. DOI: https://doi.org/10.1023/A:1021439703650 .

ZIMMER, A. \& PAHL, B. (2018): "Barriers to Third Sector Development". In: Enjolras et al., Cham, Palgrave Macmillan, 125-160. 
